\title{
RESEARCH
}

Open Access

\section{A study of diffusion tensor imaging of median nerve in diabetic peripheral neuropathy}

\author{
Ramy Edward ${ }^{1}$, Ahmed M. Abdelalim², Amal S. Ashour ${ }^{2}$, Lamia Afifi ${ }^{3}$ and Aussan Al-Athwari ${ }^{2}$
}

\begin{abstract}
Objective: To evaluate the role of diffusion tensor imaging (DTI) in the evaluation of diabetic peripheral neuropathy (DPN) compared to clinical scores and nerve conduction studies (NCS).

Patients and methods: We included 30 patients with diabetes mellitus complaining of neuropathy symptoms and 15 healthy volunteers. All subjects underwent evaluation using 1.5-T DTI of median nerves and NCS. Patients underwent clinical evaluation using the Neuropathy Deficit Score (NDS), Neuropathy Impairment Score in the Lower Limbs (NIS$\mathrm{LL}$ ), and Diabetic Neuropathy Examination (DNE) score.

Results: We found statistically significant differences between healthy volunteers and patients in fractional anisotropy (FA) of the distal segment $(P=0.016)$ and whole median nerve $(P=0.024)$, apparent diffusion coefficient (ADC) of proximal $(P=0.027)$ and distal $(P<0.001)$ segments, and whole median nerve $(P=0.019)$. Distal segment FA was significantly correlated with NDS $(P=0.003)$, DNEs $(P=0.003)$, sensory amplitude $(P=0.048)$, and motor $C V(P=0.020)$. Distal segment ADC was significantly correlated with NDS $(P=0.007)$, NIS-LL $(P=0.003)$, DNEs $(P=0.01)$, and sensory amplitude $(P=0.032)$. The best cut-off value of distal segment for FA was 0.45 ( $87 \%$ sensitivity, $80 \%$ specificity) and of distal segment ADC was 1.217 (80\% sensitivity and specificity).
\end{abstract}

Conclusions: Our results suggest that 1.5-T DTI examination of the median nerve can provide useful non-invasive information in patients with DPN.

Trial registration: ClinicalTrials.gov, NCT03934970. Registered on May 1, 2019

Keywords: Diabetic neuropathy, DTI, FA, ADC, Clinical scores, NCS

\section{Introduction}

Diabetic peripheral neuropathy (DPN) is one of the most commonly reported long-term complications of diabetes mellitus (DM), affecting up to $50 \%$ of patients [1]. Electrodiagnostic studies, when used properly, are the standard sensitive and reproducible tool for the evaluation of diabetic neuropathy [2]. In addition, clinical neuropathy scoring systems have been used as valid tools in

\footnotetext{
* Correspondence: a.aalim@kasralainy.edu.eg

${ }^{2}$ Department of Neurology, Cairo University, Giza, Egypt

Full list of author information is available at the end of the article
}

screening and evaluation of DPN [3] and have been shown to correlate well to nerve conduction studies (NCS) [4-6].

Magnetic resonance diffusion tensor imaging (DTI) has been shown to detect neuropathy even in asymptomatic patients [7]. It uses high-resolution/high-contrast spin echo-type 2D and 3D imaging sequences which include heavy T2 weighting and uniform fat suppression which makes it an excellent technique that enhances peripheral nerve anatomy and pathology [8].

The aim of this study is to evaluate the role of DTI in the detection of peripheral nerve changes in patients

\section{Springer Open}

(c) The Author(s). 2020 Open Access This article is licensed under a Creative Commons Attribution 4.0 International License, which permits use, sharing, adaptation, distribution and reproduction in any medium or format, as long as you give appropriate credit to the original author(s) and the source, provide a link to the Creative Commons licence, and indicate if changes were made. The images or other third party material in this article are included in the article's Creative Commons licence, unless indicated otherwise in a credit line to the material. If material is not included in the article's Creative Commons licence and your intended use is not permitted by statutory regulation or exceeds the permitted use, you will need to obtain permission directly from the copyright holder. To view a copy of this licence, visit http://creativecommons.org/licenses/by/4.0/. 
with diabetes mellitus in comparison to the nerve conduction studies and clinical neuropathy scoring systems.

\section{Patients and methods}

This study is a case-control study of 30 Egyptian patients with type 2 diabetes mellitus complaining of symptoms suggestive of peripheral neuropathy including 12 males and 18 females with a mean of $50.90 \pm 9.18$ years and 15 normal healthy Egyptian volunteers including 10 males and 5 females with a mean age of $45.67 \pm 7.77$ years. Patients were included consecutively from outpatient clinics, Cairo University Hospitals, Egypt, during the period between April 2015 and November 2015. The study has been approved by Cairo University Research Ethics Committee, and all patients signed informed consent before enrollment in the study.

Patients with evidence of nerve entrapment or neuropathy due to causes other than DM (drug-induced, hereditary neuropathies) were excluded.

\section{Methods}

\section{Clinical scoring systems}

Scoring of peripheral neuropathy was performed in all patients using the following:

a) Neuropathy Deficit Score (NDS) [9, 10]: The NDS is the most widely used and accepted scoring system for diabetic neuropathy. It includes the examination of vibration (using a 128- $\mathrm{Hz}$ tuning fork), sensation (pain and temperature), and ankle reflex. The score of vibration and sensation is " 0 " if present and normal and " 1 " if absent, reduced, or uncertain. The ankle reflex scores " 0 " if present and normal and "2" if absent with a maximum total score of "10". The grades of severity of neuropathy are classified as follows: mild (scores, 3-5), moderate (scores, 6-8), and severe (scores, 9-10).

b) Neuropathy Impairment Score in the Lower Limbs (NIS-LL) [11]: This score evaluates quantitatively the changes in motor, sensory, and reflex activity in the lower limbs. It examines motor power, sensations, and deep reflexes. The graded scale ranges from the normal value at "0" points, with a maximum value of 88 points when all motor, sensory, and reflex activity in the lower limbs are lost.

c) Diabetic Neuropathy Examination (DNE) score [12]: Only the limbs of the right side are examined in this score with a maximum score of 16 points. A score, greater than three, is considered abnormal.

\section{Neurophysiologic studies}

All 45 participants underwent neurophysiologic evaluation by an expert examiner in the Clinical Neurophysiology unit, Department of Neurology, Cairo University. Nerve conduction studies were performed using a Dantec NCV/ EMG machine (Keypoint, Pleasanton, CA, USA). The patient's limb was placed in a relaxed position as any movement of the limb can hamper the results, and room temperature maintained between $21-23^{\circ} \mathrm{C}$. The reduction of electrode impedance was achieved by applying electrode gel under the electrode and by affixing the electrode with adhesive tape to the skin. Median nerve motor and sensory fibers were studied on both sides. The compound muscle action potentials (CMAP) were recorded using surface recording bar electrodes and were placed over the main bulk of the abductor pollicis brevis. The sensory responses were measured by the antidromic technique using finger ring electrodes on the index finger while stimulating at the wrist. Motor stimulation was applied at the palm, the wrist, then at the mid-forearm. Velocity was calculated at the palm-wrist segment (distal segment) and at the wrist/mid-forearm segment (proximal segment).

\section{Diffusion tensor imaging (DTI)}

Imaging was performed at the Magnetic Resonance Unit, Department of Radiodiagnosis, Cairo University, using a 1.5-T magnetic resonance scanner that uses a dedicated circular wrist coil (Achieva Sense; Phillips, Best, the Netherlands). In patients and healthy volunteers, the right and left hands up to the mid-forearm were examined with the participant in the prone position and hands extended over the head ("Superman position"). Preliminary scout localizers in axial, coronal, and sagittal planes were done. A single-shot spin-echo echo-planar DTI sequence and a T1-weighted axial were used. The total duration of the sequence was $3 \mathrm{~min}$ and $50 \mathrm{~s}$, and the diffusion weighting was applied in 32 directions, with a $b$ value of $2000 \mathrm{~s} / \mathrm{mm}^{2}$.

\section{DTI post-processing}

Images were post-processed by an expert radiologist. Fractional anisotropy (FA) and apparent diffusion coefficient (ADC) maps were calculated from the raw DTI data using a specific software supplied by the vendor (Achieva Release; Phillips, the Netherlands). Circular regions of interest (ROI) were placed, according to the information from coronal and axial color-coded maps, at the expected anatomic locations of the median nerve (Fig. 1). These locations were anatomically confirmed using T1-weighted reference images (Fig. 2) with an ROI larger than the nerve excluding surrounding fat, vessels, or tendons and avoiding partial volume artifacts (Fig. 3). Three levels were selected for ROI placement: the midforearm, the distal radioulnar joint (proximal carpal tunnel); and the level of the hook of the hamate (distal carpal tunnel). The FA and ADC values at the three ROIs of the median nerve were calculated semi-automatically 


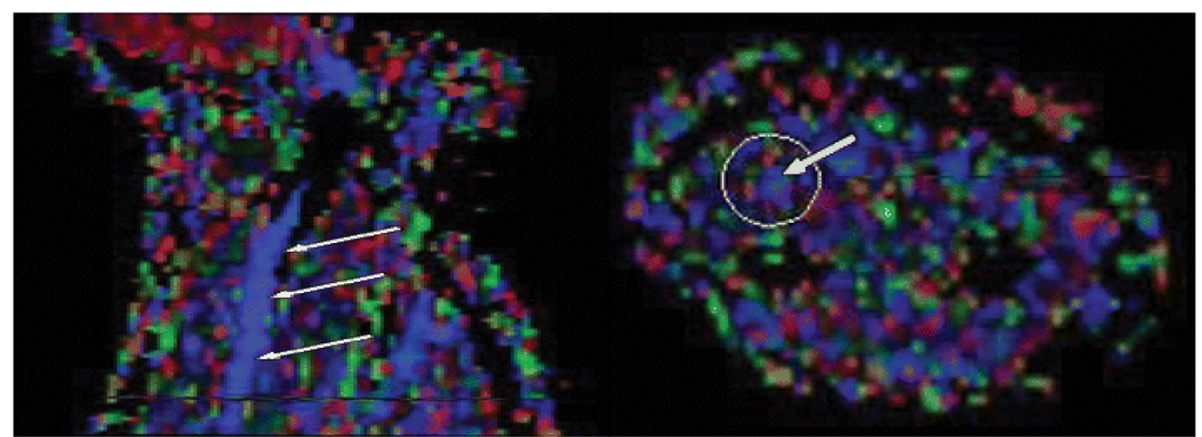

Fig. 1 Coronal color-coded map shows the median nerve (left), and axial color-coded map obtained with the aid of coronal map shows the median nerve (right)

where the average mean value between the hamate and distal radioulnar joint was considered the value for the distal segment of the median nerve, while the average mean value between the distal radioulnar joint and midforearm was considered the value of the proximal segment of the median nerve. The overall mean of all segments was then considered the "whole" nerve value. Figure 4 shows a tractographic image of the median nerve.

\section{Statistical analysis}

Analysis was performed using Statistical Package for the Social Sciences (SPSS) version 23 (IBM Inc., Chicago, IL, USA). Numerical data were expressed as mean \pm standard deviation (SD), and comparisons were performed using Student's $t$ test. Pearson's correlation coefficient $(r)$ was used to test the correlation between mean FA and mean ADC values and amplitude and conduction velocity $(\mathrm{CV})$ and clinical scores. The mean FA and ADC cut-off values for the diagnosis of diabetic neuropathy were calculated using receiver operating characteristic

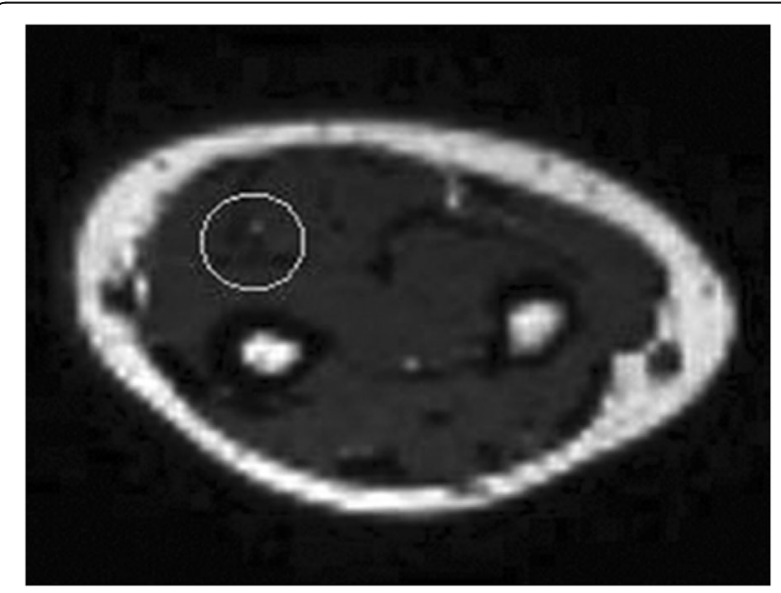

Fig. 2 Anatomic T1-weighted reference MR image confirming localization of median nerve
(ROC) curve analysis. Chi-square test was used to test distribution and associations among nominal (non-numerical data). $P$ value $<0.05$ was considered statistically significant.

\section{Results}

There were statistically significant differences between patients and healthy volunteers in FA of distal segment $(P=0.016)$ and whole median nerve $(P=0.024)$ with lower FA values in patients. There were significant differences between patients and healthy volunteers in ADC of proximal $(P=0.027)$, distal segments $(P<$ $0.001)$, and the whole median nerve $(P=0.019)$ with higher ADC values in patients (Table 1 ).

Six patients $(20 \%)$ had normal neurophysiological studies with no statistically significant differences in FA or ADC in all segments between both groups $(P>0.05)$.

There was a statistically significant correlation between FA of distal segment and sensory amplitude $(r=0.257, P=$ $0.048)$ and motor CV $(r=0.299, P=0.020)$ of distal segment and motor $\mathrm{CV}$ of proximal segment of the median nerve $(r=0.318, P=0.013)$. Whole nerve FA was statistically correlated to the sensory amplitude of distal segment $(r=0.279, P=0.031)$ (Fig. 5).

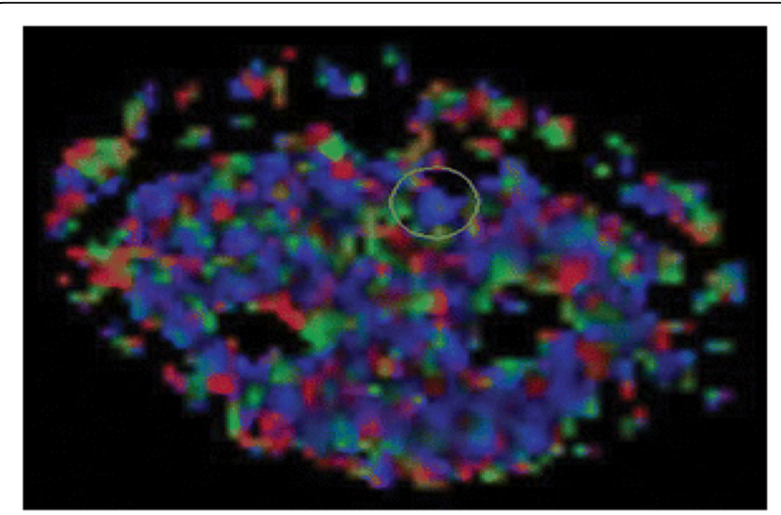

Fig. 3 Axial color-coded map shows that for tractography, region of interest is larger than nerve. 


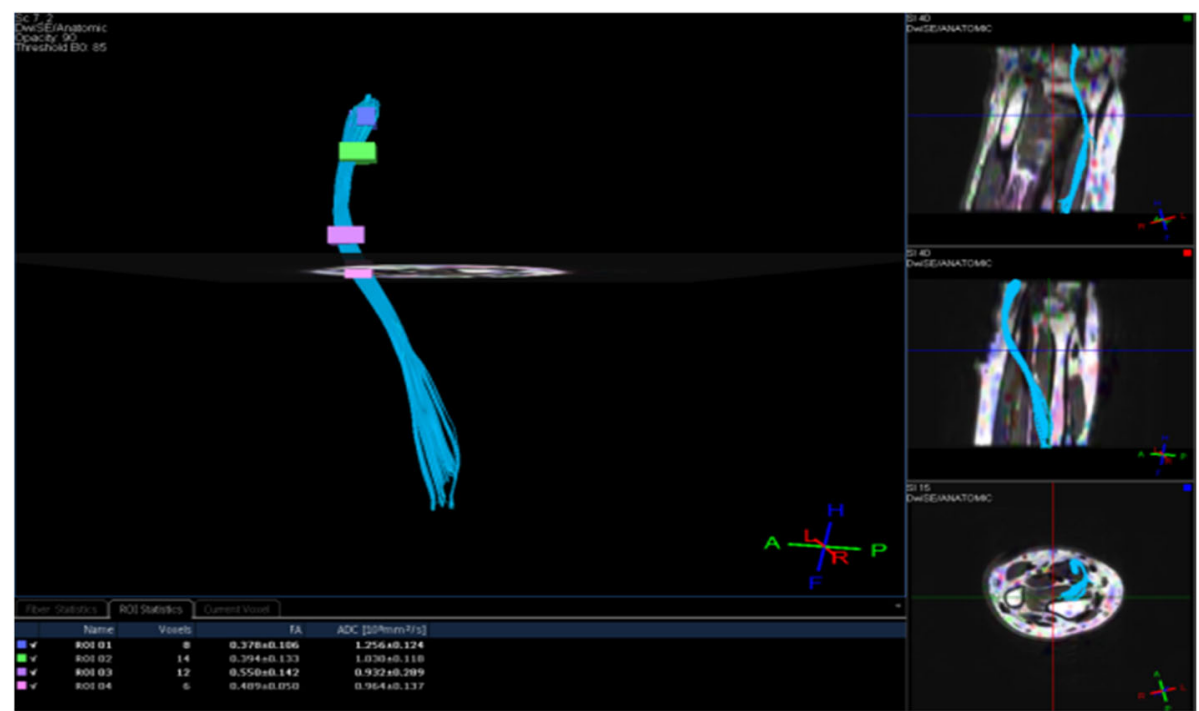

Fig. 4 Tractographic image showing median nerve

There was a statistically significant correlation between ADC of distal segment and sensory amplitude of distal segment $(r=-0.278, P=0.032)$. ADC of the whole nerve was statistically correlated to the motor $\mathrm{CV}$ of the median nerve proximal segment $(r=0.097, P=0.039)$ (Fig. 6).

Neither sensory CV nor motor amplitude of any segment was significantly correlated to any of DTI parameters.

There were statistically significant correlations between FA of median nerve distal segment and NDS $(r=$ - 0.518, $P=0.003)$ and DNEs $(r=-0.521, P=0.003)$, whereas the FA of the whole median nerve was statistically correlated to NDS $(r=-0.377, P=0.040)$ and NIS-LL $(r=-0.408, P=0.025)$ (Fig. 7 ).

There were statistically significant correlations between the ADC of the median nerve distal segment and NDS $(r=0.482, P=0.007)$, NIS-LL $(r=0.524, P=$ $0.003)$ and DNEs $(r=0.459, P=0.011)$, while there was a statistically significant correlation between ADC of the median nerve proximal segment and NIS-LL only $(r=$ $0.424, P=0.019)$. ADC of and the whole median nerve was statistically correlated to NDS $(r=0.371, P=0.044)$ and NIS-LL $(r=0.471, P=0.009)$ (Fig. 8).

The mean duration of DM was $11.8 \pm 7.61$ years, and the mean glycated hemoglobin was $9.49 \pm 1.94$. There were statistically significant correlations between FA of median nerve distal segment and duration of DM $(r=-0388, P=$ $0.034)$, but not with $\mathrm{HbA}_{1} \mathrm{C}(P>0.05)$. FA of the proximal segment and whole median nerve, ADC of distal, proximal segments, and whole fiber were not significantly correlated to the duration of DM, symptoms, nor $\mathrm{HbA}_{1} \mathrm{C}$.

The best cut-off FA value for the detection of neuropathy was 0.45 at the distal segment with a sensitivity of $87 \%$ and specificity of $80 \%$. An FA value $<0.45$ was considered abnormal. In addition, the best cut-off ADC value for the detection of neuropathy was 1.217 at the distal segment with $80 \%$ sensitivity and $80 \%$ specificity. An ADC value $>1.217$ was considered abnormal

Table 1 Comparison of DTI parameters among patients and healthy volunteers

\begin{tabular}{|c|c|c|c|c|}
\hline \multicolumn{2}{|c|}{ DTI parameter } & $\begin{array}{l}\text { Patients }(n=30) \\
\text { Mean } \pm \text { SD }\end{array}$ & $\begin{array}{l}\text { Healthy volunteers }(n=15) \\
\text { Mean } \pm \text { SD }\end{array}$ & $P$ value \\
\hline \multirow[t]{3}{*}{$F A$} & Proximal segment & $0.49 \pm 0.05$ & $0.51 \pm 0.10$ & 0.357 \\
\hline & Distal segment & $0.42 \pm 0.04$ & $0.46 \pm 0.05$ & $0.016^{*}$ \\
\hline & Whole nerve & $0.44 \pm 0.09$ & $0.52 \pm 0.12$ & $0.024^{*}$ \\
\hline \multirow[t]{3}{*}{ ADC } & Proximal segment & $1.196 \pm 0.199$ & $1.070 \pm 0.112$ & $0.027^{*}$ \\
\hline & Distal segment & $1.379 \pm 0.209$ & $1.149 \pm 0.064$ & $0.000^{* *}$ \\
\hline & Whole nerve & $1.267 \pm 0.206$ & $1.111 \pm 0.194$ & $0.019^{*}$ \\
\hline
\end{tabular}

$A D C$ apparent diffusion coefficient, $D T /$ diffusion tensor imaging, $F A$ fractional anisotropy 


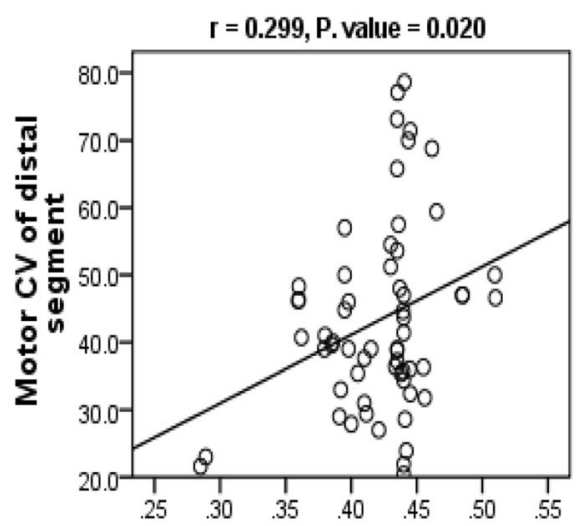

FA of distal segment

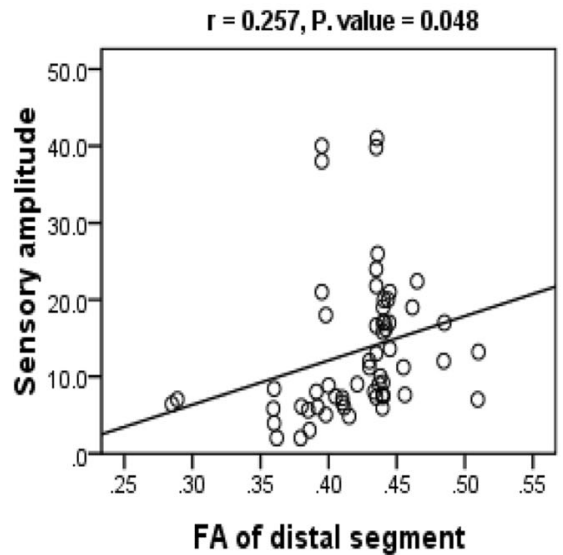

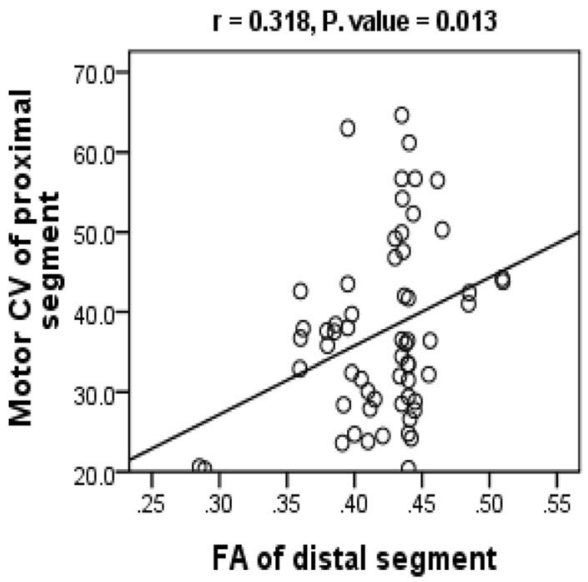

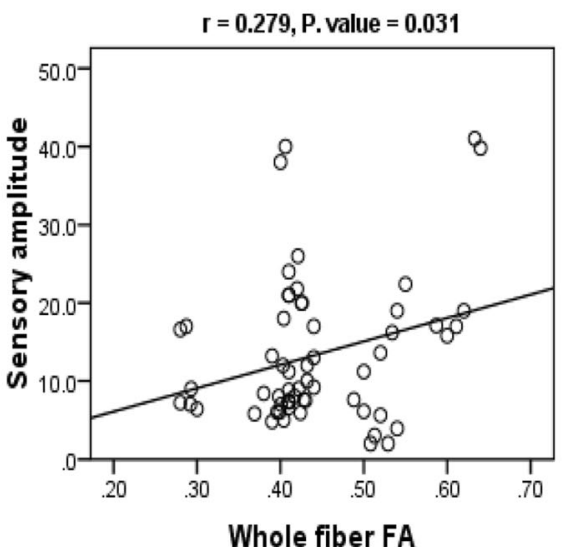

Fig. 5 Correlation of FA of distal segment with distal segment motor CV (left upper), with distal segment motor CV (right upper), and with sensory amplitude (left lower) of the median nerve. Correlation of whole median nerve FA with sensory amplitude of distal segment (right lower). ADC, apparent diffusion coefficient; CV, conduction velocity; FA, fractional anisotropy
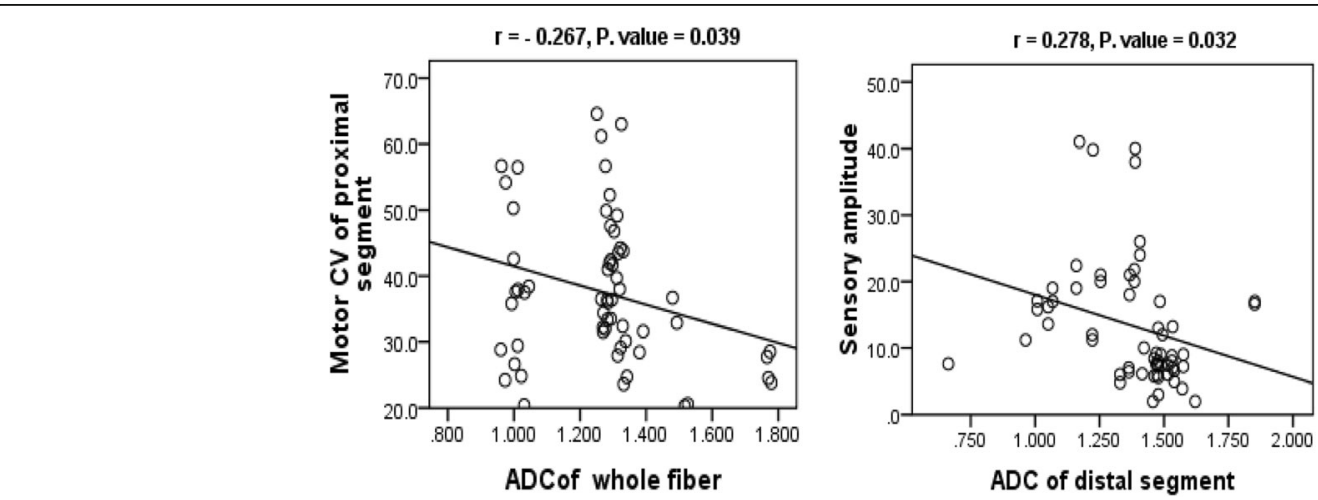

Fig. 6 Correlation between whole median nerve ADC and proximal motor conduction velocity (left) and correlation between distal segment ADC and distal sensory amplitude (right). ADC, apparent diffusion coefficient 

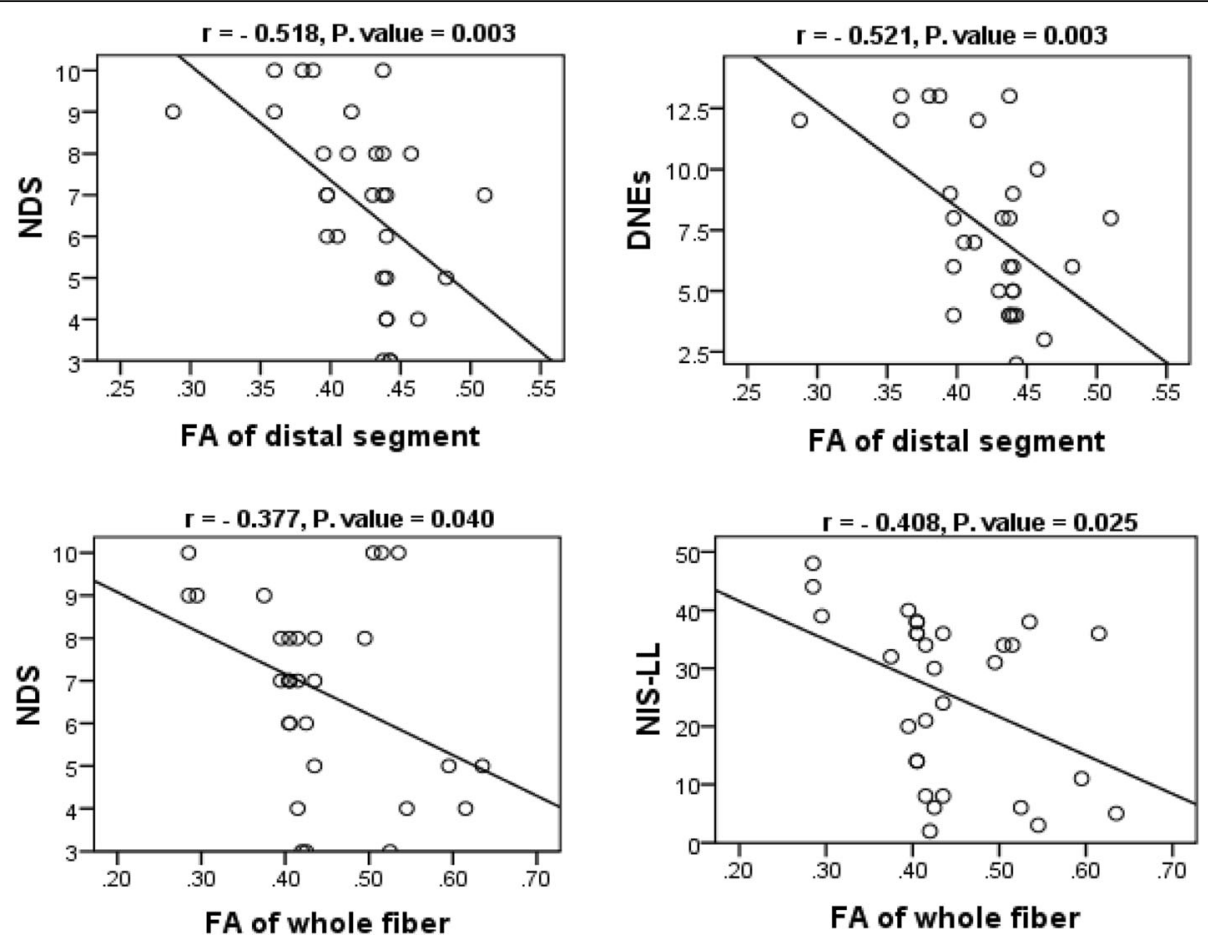

Fig. 7 Correlation of FA of distal median nerve segment with NDS (left upper) and with DNEs (right upper) and of FA of whole fiber with NDS (left lower) and with NIS-LL (right lower). DNEs, diabetic neuropathy examination score; FA, fractional anisotropy; NDS, neuropathy deficit score; NIS-LL, neuropathy impairment score in the lower limbs

\section{Discussion}

In the current study, we found statistically significant differences between patients and healthy volunteers in terms of FA of both the distal segment and whole median nerve and ADC of both proximal and distal segments and the whole median nerve.

To the best of our knowledge, this is the first study that detects DPN by studying distal median nerves using 1.5-T DTI and compares it to clinical scoring systems and NCS findings. In our study, we measured the FA and $\mathrm{ADC}$ at three ROIs, mid-forearm, distal radioulnar joint, and hamate bone levels, and we did not depend on reading at a single ROI as performed in other studies [13].

Although DTI MRI has been shown to be a feasible technique for visualization of the median nerve [13, 14], limited studies are available in the literature with respect to the use of DTI in the evaluation of different types of systemic neuropathy [15-17]. On the other hand, several studies were conducted to diagnose entrapment neuropathy using DTI. Patients with carpal tunnel syndrome were found to have significant differences in FA and ADC values compared to healthy volunteers [18-20].

In the present study, there were no statistically significant differences in FA and ADC values between patients with normal and abnormal NCS results. Yet, the number of patients with normal NCS in our study was too small $(n=6)$ to draw conclusions. Studies show that DTI can detect neuropathy as good as nerve conduction studies or may even be better in asymptomatic patients $[7,16]$.

There was a statistically significant correlation between sensory amplitude, motor CV, and FA of distal segment of the median nerve. Previous studies show that FA correlates to NCS [16, 21], but these studies used 3-T MRI. Although the significance of FA as a marker of axon integrity versus myelin integrity has been a matter of controversy, it is more likely to reflect axonal integrity $[17,21,22]$.

In addition, statistically significant negative correlations were found between FA of the distal segment of the median nerve and the NDS and DNEs. Meanwhile, the distal segment ADC had a statistically significant correlation with all clinical scoring systems used (NDS, NIS-LL, and DNEs). To the best of our knowledge, this is the first study of patients with peripheral neuropathy to correlate DTI of a peripheral nerve to clinical neuropathy scoring systems in diabetic patients.

We found a statistically significant correlation between FA of median nerve distal segment and duration of DM, but not $\mathrm{HbA}_{1} \mathrm{C}(P>0.05)$. We found no literature correlating those parameters to DTI, yet these results could be explained in the context of axonal damage reflected by FA and caused by DM along the disease course rather than the glycemic control in the few months that preceded the study. 


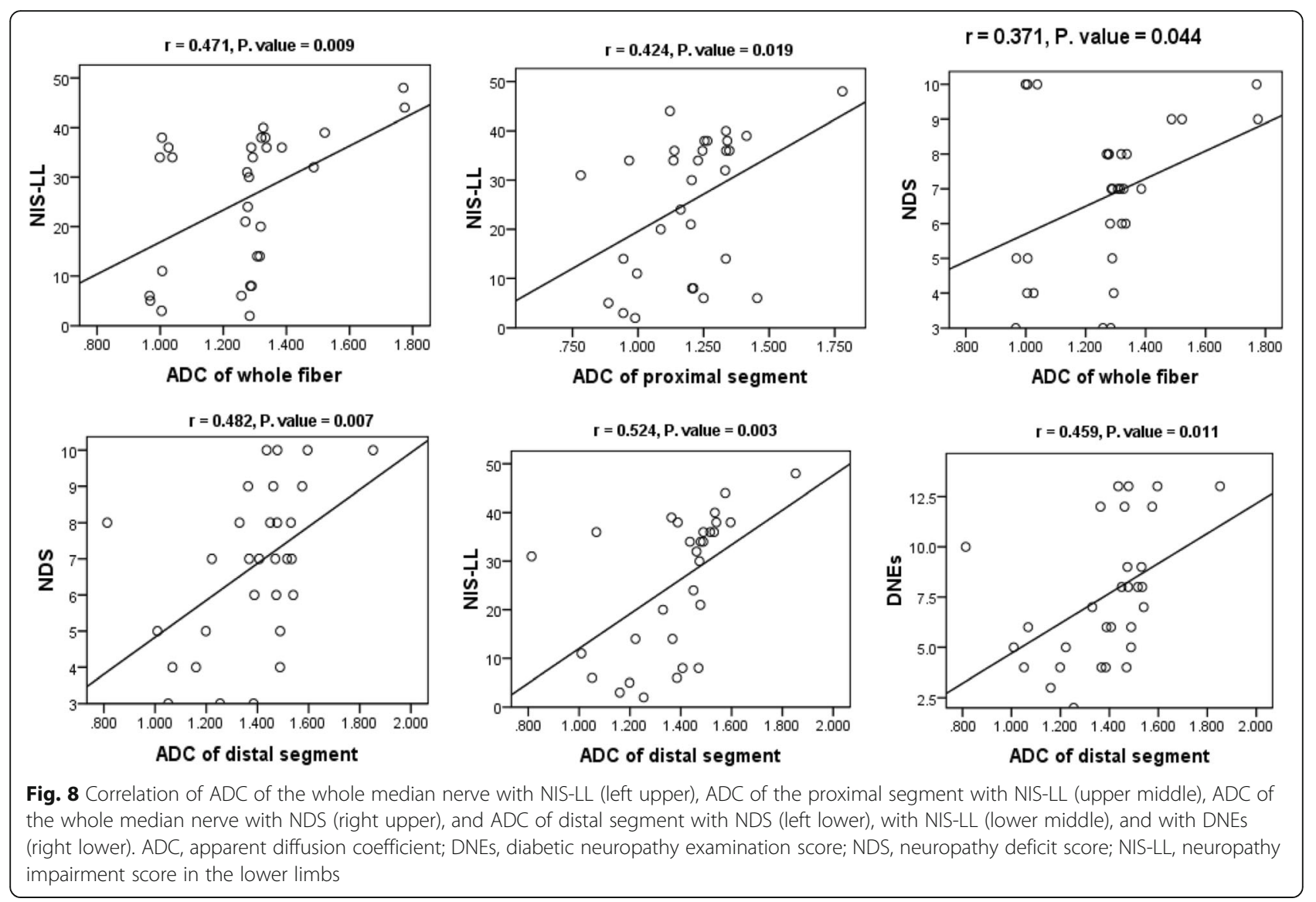

We found the best cut-off values identifying neuropathy to be a distal segment FA value of 0.45 with $87 \%$ sensitivity and $80 \%$ and a distal segment ADC value of 1.217 with $80 \%$ sensitivity and specificity. Lower FA and higher ADC values signify neuropathy.

Refining our results, we find that the best significant values obtained were by measuring FA and ADC values of the distal segment of the median nerve. Generally, we find DTI of the median nerve a feasible technique, being easy to trace and to perform measurements upon.

The current study carries some limitations, which are mostly related to the limited sample size (limited mainly by MRI feasibility), lack of gender matching. In addition, another limiting factor was the use of 1.5-T MRI, whereas $3 \mathrm{~T}$ might have yielded better results.

\section{Conclusions}

In conclusion, 1.5-T DTI of the median nerve offers a feasible, non-invasive technique that is capable of diagnosing peripheral neuropathy in diabetic patients and may be as effective and valuable as neurophysiological studies and clinical scoring systems in both clinical practice and research of peripheral neuropathy.

\section{Abbreviations}

ADC: Apparent diffusion coefficient; CMAP: Compound muscle action potentials; CV: Conduction velocity; DM: Diabetes mellitus; DNE: Diabetic Neuropathy Examination; DPN: Diabetic peripheral neuropathy; DTI: Diffusion tensor imaging; FA: Fractional anisotropy; MRI: Magnetic resonance imaging; NCS: Nerve conduction studies; NDS: Neuropathy Deficit Score; NISLL: Neuropathy Impairment Score in the Lower Limbs; ROC: Receiver operating characteristic; ROI: Region of interest; SD: Standard deviation

\section{Acknowledgements}

Not applicable

\section{Authors' contributions}

All authors contributed to the conception and design of the study. AA and ASA performed the data collection. RE performed the MRI technique and data acquisition. LA performed the NCS technique and data acquisition. AMA performed the statistical analysis. All Authors participated in data interpretation and analysis, revised and approved the final draft, and hold responsibility for the accuracy and integrity of all aspects of the study.

\section{Funding}

None

Availability of data and materials

The datasets generated and analyzed during the current study can be available upon reasonable request from the corresponding author.

\section{Ethics approval and consent to participate}

This study was approved by The Research Ethics Committee of the Faculty of Medicine, Cairo University, on the 19th of April 2015. All subjects provided signed written informed consent prior to participating in the study. 


\section{Consent for publication}

Not applicable

\section{Competing interests}

The authors declare that they have no competing interests.

\section{Author details}

'Department of Radiodiagnosis, Cairo University, Giza, Egypt. ${ }^{2}$ Department of Neurology, Cairo University, Giza, Egypt. ${ }^{3}$ Clinical Neurophysiology Unit, Cairo University, Giza, Egypt.

Received: 17 November 2019 Accepted: 30 March 2020 Published online: 16 April 2020

\section{References}

1. Hussain G, Rizvi SA, Singhal S, Zubair M, Ahmad J. Cross sectional study to evaluate the effect of duration of type 2 diabetes mellitus on the nerve conduction velocity in diabetic peripheral neuropathy. Diabetes Metab Syndr. 2014;8(1):48-52.

2. Vinik Al, Kong X, Megerian JT, Gozani SN. Diabetic nerve conduction abnormalities in the primary care setting. Diabetes Technol Ther. 2006;8(6): 654-62.

3. Zilliox LA, Ruby SK, Singh S, Zhan M, Russell JW. Clinical neuropathy scales in neuropathy associated with impaired glucose tolerance. J Diabetes Complications. 2015;29(3):372-7.

4. Feki I, Lefaucheur JP. Correlation between nerve conduction studies and clinical scores in diabetic neuropathy. Muscle Nerve. 2001;24(4):555-8.

5. Asad A, Hameed MA, Khan UA, Butt MU, Ahmed N, Nadeem A. Comparison of nerve conduction studies with diabetic neuropathy symptom score and diabetic neuropathy examination score in type-2 diabetics for detection of sensorimotor polyneuropathy. J Pak Med Assoc. 2009;59(9):594-8.

6. Asad A, Hameed MA, Khan UA, Ahmed N, Butt MU. Reliability of the neurological scores for assessment of sensorimotor neuropathy in type 2 diabetics. J Pak Med Assoc. 2010;60(3):166-70.

7. Kollmer J, Bendszus M, Pham M. MR Neurography: diagnostic imaging in the PNS. Clin Neuroradiol. 2015;25(Suppl 2):283-9.

8. Thakkar RS, Del Grande F, Thawait GK, Andreisek G, Carrino JA, Chhabra A Spectrum of high-resolution MRI findings in diabetic neuropathy. AJR Am J Roentgenol. 2012;199(2):407-12.

9. Cabezas-Cerrato J. The prevalence of clinical diabetic polyneuropathy in Spain: a study in primary care and hospital clinic groups. Neuropathy Spanish Study Group of the Spanish Diabetes Society (SDS). Diabetologia. 1998;41(11):1263-9.

10. Dyck PJ, Davies JL, Litchy WJ, O'Brien PC. Longitudinal assessment of diabetic polyneuropathy using a composite score in the Rochester Diabetic Neuropathy Study cohort. Neurology. 1997;49(1):229-39.

11. Bril V. NIS-LL: the primary measurement scale for clinical trial endpoints in diabetic peripheral neuropathy. Eur Neurol. 1999;41(Suppl 1):8-13.

12. Meijer JW, van Sonderen E, Blaauwwiekel EE, Smit AJ, Groothoff JW, Eisma WH, et al. Diabetic neuropathy examination: a hierarchical scoring system to diagnose distal polyneuropathy in diabetes. Diabetes Care. 2000;23(6):750-3.

13. Khalil C, Hancart C, Le ThuC V, Chantelot C, Chechin D, Cotten A. Diffusion tensor imaging and tractography of the median nerve in carpal tunnel syndrome: preliminary results. Eur Radiol. 2008;18(10):2283-91.

14. Zhou Y, Kumaravel M, Patel VS, Sheikh KA, Narayana PA. Diffusion tensor imaging of forearm nerves in humans. J Magn Reson Imaging. 2012;36(4): 920-7.

15. Tanitame K, Iwakado Y, Akiyama Y, Ueno H, Ochi K, Otani K, et al. Effect of age on the fractional anisotropy (FA) value of peripheral nerves and clinical significance of the age-corrected FA value for evaluating polyneuropathies. Neuroradiology. 2012;54(8):815-21.

16. Bäumer P, Pham M, Ruetters M, Heiland S, Heckel A, Radbruch A, et al. Peripheral neuropathy: detection with diffusion-tensor imaging. Radiology. 2014;273(1):185-93.

17. Kakuda T, Fukuda H, Tanitame K, Takasu M, Date S, Ochi K, et al. Diffusion tensor imaging of peripheral nerve in patients with chronic inflammatory demyelinating polyradiculoneuropathy: a feasibility study. Neuroradiology. 2011;53(12):955-60.

18. Hiltunen J, Suortti T, Arvela S, Seppä M, Joensuu R, Hari R. Diffusion tensor imaging and tractography of distal peripheral nerves at $3 \mathrm{~T}$. Clin Neurophysiol. 2005;116(10):2315-23.
19. Stein D, Neufeld A, Pasternak O, Graif M, Patish H, Schwimmer E, et al. Diffusion tensor imaging of the median nerve in healthy and carpal tunnel syndrome subjects. J Magn Reson Imaging. 2009;29(3):657-62.

20. Tasdelen N, Gurses B, Kilickesmez O, Firat Z, Karlikaya G, Tercan M, et al. Diffusion tensor imaging in carpal tunnel syndrome. Diagn Interv Radiol. 2012;18(1):60-6.

21. Heckel A, Weiler M, Xia A, Ruetters M, Pham M, Bendszus M, et al. Peripheral nerve diffusion tensor imaging: assessment of axon and myelin sheath integrity. PLoS One. 2015;10(6):e0130833.

22. Mathys C, Aissa J, Meyer Zu Hörste G, Reichelt DC, Antoch G, Turowski B, et al. Peripheral neuropathy: assessment of proximal nerve integrity by diffusion tensor imaging. Muscle Nerve. 2013;48(6):889-96.

\section{Publisher's Note}

Springer Nature remains neutral with regard to jurisdictional claims in published maps and institutional affiliations.

\section{Submit your manuscript to a SpringerOpen ${ }^{\circ}$ journal and benefit from:}

- Convenient online submission

- Rigorous peer review

- Open access: articles freely available online

- High visibility within the field

- Retaining the copyright to your article

Submit your next manuscript at $\boldsymbol{\nabla}$ springeropen.com 